\title{
Subbens checklist
}

\author{
Torbjörn Larsson and Michael Patriksson \\ Journal Article
}

\section{Tweet}

N.B.: When citing this work, cite the original article.

Original Publication:

Torbjörn Larsson and Michael Patriksson, Subbens checklist, Computers\&Operations Research, 2016. 71, pp.163-164.

http://dx.doi.org/10.1016/j.cor.2016.02.004

Copyright: Elsevier

http://www.elsevier.com/

Postprint available at: Linköping University Electronic Press

http://urn.kb.se/resolve?urn=urn:nbn:se:liu:diva-128918

(9) $(1) \Theta$ 


\title{
"Subben's checklist" and the assessment of articles in mathematical optimization/operations research: in memoriam of Subhash C. Narula
}

\author{
Torbjörn Larsson ${ }^{\mathrm{a}}$, Michael Patriksson ${ }^{\mathrm{b}, *}$ \\ ${ }^{a}$ Department of Mathematics, Linköping University, Linköping, Sweden \\ ${ }^{b}$ Department of Mathematical Sciences, Chalmers University of Technology, and \\ Department of Mathematical Sciences, University of Gothenburg, Gothenburg, Sweden
}

\begin{abstract}
Excellent guides on academic writing and presentation in science in general, and in mathematics and computer science in particular, do abound (see, for example, [KLR89, All96, Kra96, Hig98, Mon02, Kra05, Kra07, PeK10]), while guides on the assessment of the results of academic writing are rather more scarce. This short article presents two itemized lists that may be helping hands during the assessment of a scientific article in the field of mathematical optimization and operations research-be it your own, a work by a Master or PhD student of yours, or even a manuscript that you are refereeing for a scientific journal or conference proceedings volume.

The first list - "Subben's checklist" - describes necessary ingredients of a complete article. The second list provides criteria for assessing the quality and scientific value of an article.
\end{abstract}

Keywords: Academic writing, editing, evaluation 2000 MSC: 90-00, 90-01, 90-02

\footnotetext{
*Corresponding author

Email addresses: torbjorn.larsson@liu.se (Torbjörn Larsson), mipat@chalmers.se (Michael Patriksson)

This article is dedicated to professor Subhash C. Narula, and the fond memories of him. The authors would also like to thank Dr. Peter Kumlin at Mathematical Sciences, Chalmers, for valuable comments on a previous version of this paper, and the Consulting Editor Prof. Dr. Stefan Nickel and the Editor-in-Chief Dr. Francisco Saldanha da Gama for support and additional remarks on a previous version of this paper.
} 


\section{Introduction}

One day in the spring of 1993 the authors had a very interesting conversation with Professor Subhash C. Narula - our then head of the division of optimization at the Department of Mathematics, Linköping University, Linköping, Sweden. The topic of the conversation, which took place in his office, concerned the fundamental principles of article writing.

We specifically discussed what - in our field of study (quantitative operations research in general, and mathematical optimization in particular) constitutes the necessary and sufficient core content of any complete research article. The authors of this paper now believe that this discussion emanated from all of us then recently having had the unfortunate duty to be referees on rather poorly written manuscripts - in our optinion: even incomplete ones! - and hence we discussed not only the quality of articles in general, but in particular if there were simple ways to assess and characterize an article's "completeness," as well as its qualities.

In the following section we provide the result of this discussion on the assessment of an article: "Subben's checklist". In Section 3 we then complement this list with a more general discussion on how scientific work can be evaluated.

\section{2. "Subben's checklist"}

Professor Subhash Narula - fondly nicknamed "Subben" by the research group in mathematical optimization, hence the name of the list in Table 1 below - had a clear vision of his viewpoint on the assessment of an article, and could rather quickly establish a few "items" that necessarily must be in place in any article in our field, in order for it to possibly be considered complete. The authors of this article also contributed, and notes were taken on the occasion by the corresponding author of the current paper. These notes have since then been slightly updated, and is stored at a place always ready at hand - as one never knows when the list may come in handy!

During the years this list - and the corresponding phrases - has expanded slightly. Some 20 years after the above-mentioned conversation occured the corresponding author was enrolled in a $\mathrm{PhD}$ course on scientific methodology at Chalmers University of Technology, called "Theory and Methodology of Science", and whose students (masters students as well as $\mathrm{PhD}$ students) typically had research topics within finance and logistics. During a few years 
of enrollment in this course he gave assignments to these students, in which they were asked to read articles in an unfamiliar scientific domain (namely: quantitative OR papers - classical ones as well as papers of the authors of this article), to try to pinpoint whether all the items in Subben's checklist were in fact covered. The students did a very good job, despite the fact that many of them were not PhD students in a quantitative field of study. Partly thanks to this fact, the corresponding author was subjected to a suggestion to add to the list the now sixth item ("Methodology"), motivated by the fact that in some fields of study represented by the students, there were several possible approaches to attacking a given problem.

Table 1 shows the current version of "Subben's checklist" of necessary items in a complete OR paper, sorted roughly in the order that they may often be revealed, and supplied with brief descriptions.

Table 1: Subben's checklist

\begin{tabular}{|c|c|c|}
\hline & Relevance & Motivation of study; need, benefit; why interesting? \\
\hline & Background & $\begin{array}{l}\text { History, references, state-of-the-art; framework, } \\
\text { delimitations }\end{array}$ \\
\hline 3. & Resea & Shortcomings in existing knowledge or methodology \\
\hline 4. & Remed & $\begin{array}{l}\text { Proposal of actions in order to remove the lack } \\
\text { of existing knowledge or methodology }\end{array}$ \\
\hline 5. & Нyро & Description of the research question(s) considered \\
\hline 6. & Method(ology & thodology \\
\hline 7 . & Realization & Presentation of the new scientific contributions \\
\hline 8. & Analysis & $\begin{array}{l}\text { Validation of results, conclusions, consequences, } \\
\text { and applications; future research opportunities }\end{array}$ \\
\hline
\end{tabular}

\section{Criteria for evaluating science}

The second contribution of this short article is an itemed list of criteria by which science can be evaluated. It covers scientific questions, as well as research, and results from such research, and has been assembled by the authors during a period of more than 10 years.

Relevance Is the research question (RQ) motivated by any needs, or potential benefits of any results obtained? (Relevance can be internal [for 
the scientific subject itself] or external [for practice].)

Scientific foundation Are the RQ and research work based on a solid foundation in theory and/or methodology?

Generality How comprehensive is the RQ, and how universally applicable are the results?

Consistency Are the claims and levels of ambition stated in the motivation consistent with the results and conclusions?

Availability Is the work presented in such a way that it may be critically scrutinized? Has it been appropriately described and disseminated? (For example, are numerical experiments reproducible?)

Scientific height and depth How big is the progress, and the difficulty of reaching it?

Originality Are the RQ or methodology unique, creative or innovative, or of the established kind?

News value Is there a current interest in the RQ and the results (within, or outside of, the scientific world)?

Integration How much previous knowledge is improved/summarized in this work? Does/can the work connect several scientific fields - in the paper or in possible future research?

Consequences How big is the (potential) influence and usefulness of the work (within or outside of the scientific field)? (Both can be about practical applicability and knowledge advancement in a field.)

Realization Is the research approach and methodology appropriate? Have they been used correctly? Is the work logically and technically correct?

Durability Have the RQ and results a short or a long life? (Are they, for example, technology dependent?) 


\section{Discussion}

While we have used the scientific article as the basis for the discussion, much of the above applies also to the scrutinization of other outlets of scientific investigations, as well as to applications to research foundations.

As a final note, we have two suggestions to the reader: (a) The next time you prepare an application to a research foundation, write a manuscript, or read someone elses work as a reviewer, examiner, or supervisor, try to use the above lists in order to assess what you are writing or reading. (b) If you have any comments on the lists, please contact the authors, who would be very happy to receive them.

\section{References}

[All96] M. Alley, The Craft of Scientific Writing, Springer-Verlag, New York, NY, 1996.

[Hig98] N. J. Higham, Handbook of Writing for the Mathematical Sciences, third edition, SIAM, Philadelphia, PA, 1998.

[KLR89] D. E. Knuth, T. L. Larrabee, and P. M. Roberts, Mathematical Writing, Mathematical Association of America, Washington, D.C., 1989.

[Kra96] S. G. Krantz, A Primer of Mathematical Writing, Being a Disquisition on Having Your Ideas Recorded, Typeset, Published, Read, and Appreciated, American Mathematical Society, Providence, RI, 1996.

[Kra05] S. G. Krantz, Mathematical Publishing, A Guidebook, American Mathematical Society, Providence, RI, 2005.

[Kra07] S. G. Krantz, How to write your first paper, Notices of the AMS, vol. 54, no. 11 (November), pp. 1507-1511, 2007.

[Mon02] S. L. Montgomery, The Chicago Guide to Communicating Science, University of Chicago Press, Chicago, IL, 2002.

[PeK10] A. M. Penrose and S. B. Katz, Writing in the Sciences: Exploring Conventions of Scientific Discourse, Third edition, Pearson Longman, New York, NY, 2010. 